\title{
Attaining High Standards of Safety and Health Through Sustainable Development of Dimensional Limestone (Kotah Stone): A Success Story
}

\section{Er Satish Chand Agarwal Fie}

ASI (K) Ltd, Kota, Rajasthan, India

\section{Email address:}

scagarwal42@yahoo.com

\section{To cite this article:}

Er Satish Chand Agarwal Fie. Attaining High Standards of Safety and Health Through Sustainable Development of Dimensional Limestone (Kotah Stone): A Success Story. Journal of Chemical, Environmental and Biological Engineering. Vol. 4, No. 2, 2020, pp. 47-52. doi: $10.11648 /$ j.jcebe.20200402.13

Received: January 2, 2020; Accepted: June 4, 2020; Published: June 16, 2020

\begin{abstract}
The State of Rajasthan has been gifted with unique mineral reserves of dimensional limestone widely known as Kotah Stone spreading over an area of over $55 \mathrm{sq} \mathrm{km}$. The conventional manual mining of Kotah Stone, has been going on since 1945 but all manual. It has not only degraded the environment severally but also proved to be unsafe. Major part of human efforts has been wasted in non-productive jobs causing excessive fatigue and mental stress, inflicting excessive injuries to eye, leg, foot, arm, fingers and spinal cord. Some time in 1992 industry stood on economical threshold when it felt necessary either to develop an appropriate mining technology or close down all mining activities. A responsible mining technology was innovated by the author based on concept of in-situ cutting \& sizing prior to splitting. The process has eliminated many hazardous manual process resulting in sharp reduction in accidents human fatigue and stress. Frequency of accident has reduce to $1 / 6^{\text {th }}$ : Man days lost per lac sqft of production has also reduce from 36.6 to 13 only. Major part of non-productive effort has been converted in productive increasing productivity by 3.5 times. It has also created cool and clean working environment which keeps worker calm and tolerant and alert against any danger. The technology proved to be blessings for all stake holders. The innovation has fulfilled objectives defined for Responsible mining such as respect for human rights and aspirations of affected community, providing safe, healthy, and respectful workplace, mininimising harm to environment and leaving positive legacy.
\end{abstract}

Keywords: Manual, Innovative, Safety, Kotah Stone

\section{Introduction}

Loss of human life or limb is the most painful, tragedic and irreparable event in life. Mining is one of the most hazardous industry where we fight against the nature. As it is nature rests in full equilibrium but any excavation or extraction disturbs the equilibrium leading to accidents endangering the human life. Mining has a recorded history where humanity has suffered big loss.

Engineering and technology owes a big responsibility of improving upon quality of life by innovating new methods so that human sufferings are reduced. Satisfactory living environment is very important so that working force may feel high standards of safety and comfort.

For every incidence or accident there is reason for it. There may be faulty planning or poor layout, defective tools, faulty practice causing excessive fatigue and overstressing the human body, causing human failure. At times there are unpredictable or unforeseen natural causes. Some such conditions had prevailed in dimensional limestone (Kotah Stone) mining which employing large workforce.

\section{Occurrence \& Mining Kotah Stone}

The State of Rajasthan has been blessed with vast deposit of dimensional limestone commercially marketed as Kotah Stone. The vast deposit of Kotah Stone covers over hundred villages spreading over $+55 \mathrm{sq} \mathrm{Km}$ of Ramganjmandi and Chechat Tehsil in Kota distt. 


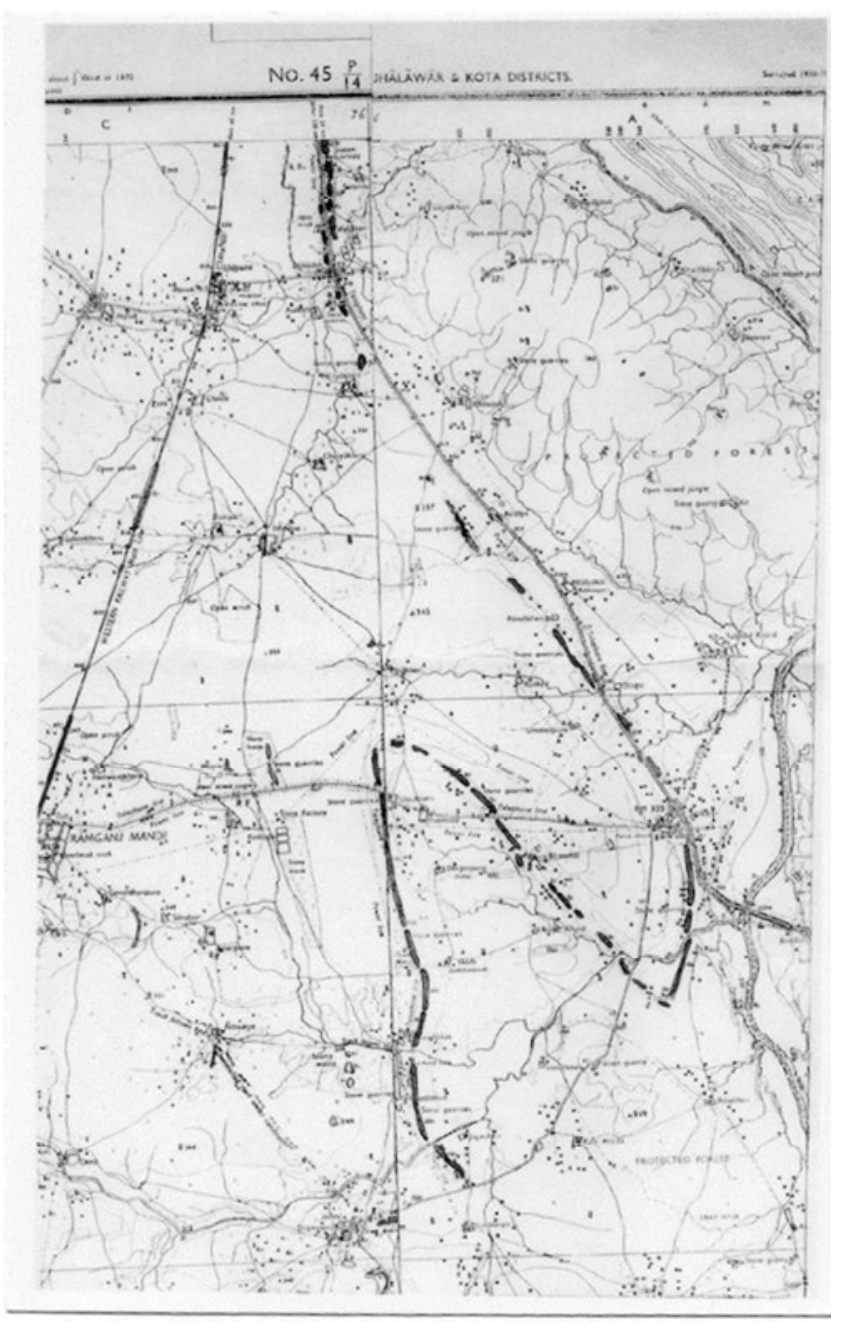

Figure 1. Occurrence of Kotah Stone.

Another large area in Jhalawar district. Mining industry is providing employment to over 2 Lac workers of which $+80 \%$ are inhabitants from local villages, both male and females. Mining for Kotah Stone has been going in since 1945 but all manual till 1992. Manual mining faced many challenges such as low productivity, poor standards of safety, high generation of waste, poor mineral conservation and poor earning created economical, environmental and social crises. In 1992 it was on threshold of closure of mining operations or innovate appreciate technology to improve the status.

\subsection{Status of Manual Mining}

Mining for Kotah stone has been going on since 1945 when mineral was outcropping on surface when $\mathrm{OB}$ waste was nil. It was all manual and continued till OB increased to $12 \mathrm{mtr}$ in 1992. Since mining was all manual the recovery was some $45 \%$, the stripping ratio was $1: 3$ (mineral to waste). The high strip ratio and low priced product the industry was on economical threshold when it became mandatory to either innovate better technology or closed down mining operation.

Manual mining had included the four major activities:

Cutting recess manually by chiesel and hammer to a depth of 3 " to create free face, in long sheet of Kotah Stone,
Separating layers from natural bondage with next layer using crowbars,

Splitting the non -dimensional chunk of Kotah Stone using chiesel and hammer along natural cleavage planes to yield thin splits,

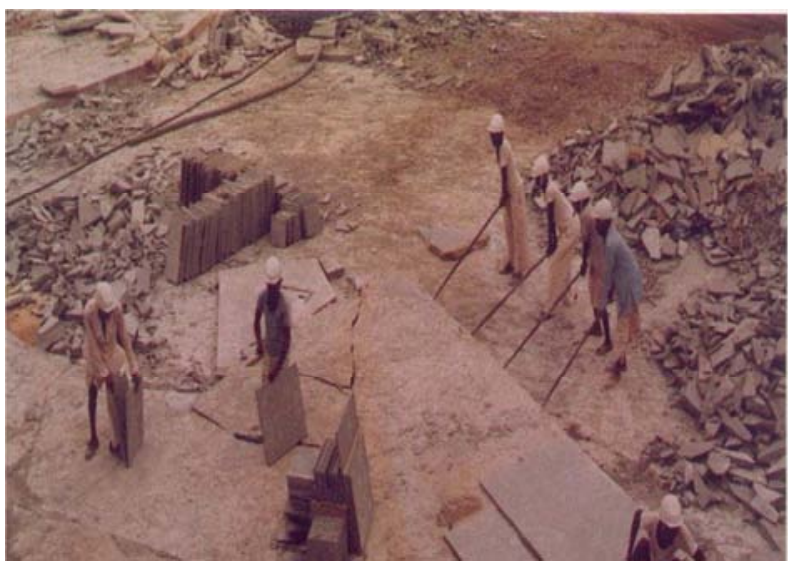

Figure 2. Manual Quarring of Kotah Stone.

The Kotah stone slabs/tiles so produced we're carried out of pit as headload to load the truck for transporting to surface. All the above production activities we're done manually exposing high accidental risk to persons working. Minor to serious injuries to fingers, hand, leg, foot, eyes and even forehead were on record. Fracture injuries and even fatal injuries were on record. Due to large production waste lying on working floor many injuries/ even fatal accidents due to slipping and knocking down while carrying head load we're common cause of accidents. Many accidents had taken during transfer of product as headload outside the pit due to accidental breakage of slab or slipping/ knocking down due to uncleaned floor.

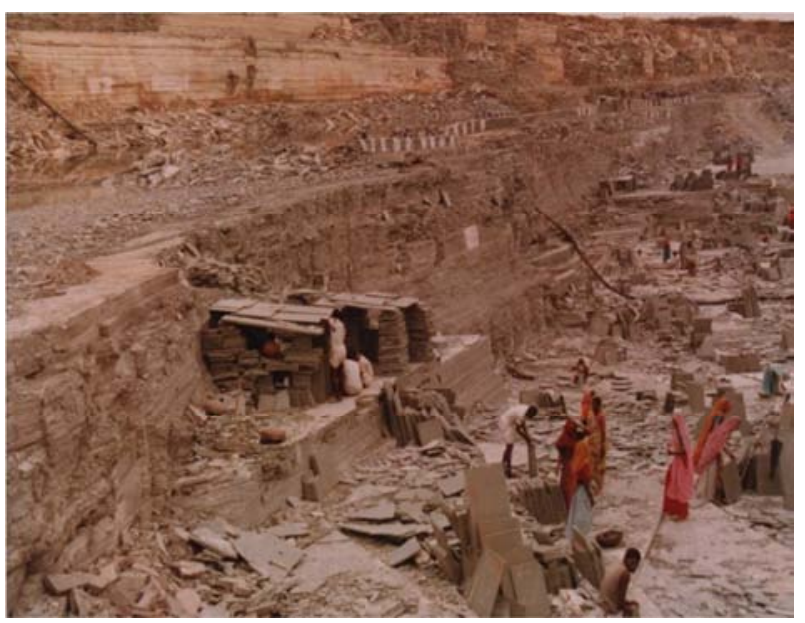

Figure 3. Uncleaned Floor in Manual Mining.

\subsection{Best Practice and Responsible Mining for Kotah Stone}

To address economic, safety \& health and environmental issues arising from manual mining, an innovative mining technology was evolved by the author. The concept is to first cut the layers in- situ before the layers of Kotah Stone. 


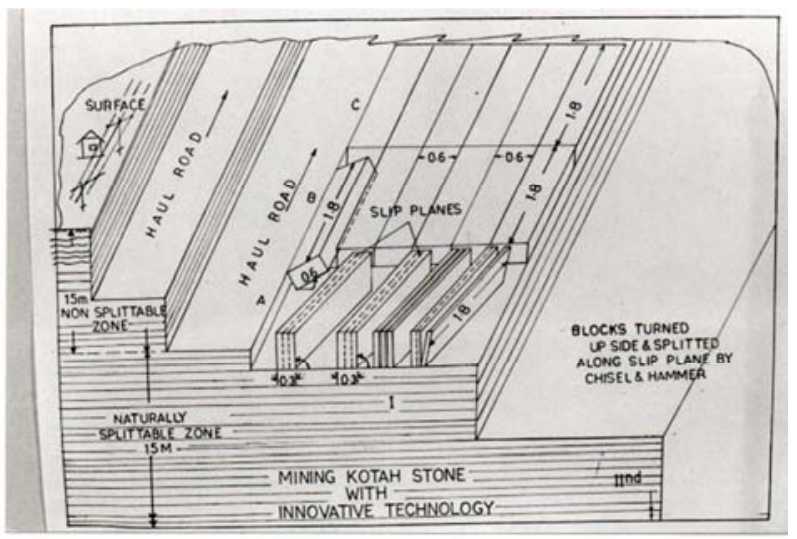

Figure 4. Conceptual Layout of Working with Innovative Technalogy.

Blocks are cut in desired width and length. Width is generally 2'. All sides cut blocks are then separated from natural bondage with crowbar giving gentle leverage. These are then splitted along cleavage plane to yield all sides cut single solid slab/ tile.

For cutting the layers of Kotah Stone in- situ portable electrically operated machine fitted with 36 " dia steel blades were designed and perfected. The steel blades are tipped with diamond impregnated segments 64 in numbers. These machines locally known as Jhiri $\mathrm{m} / \mathrm{c}$ are operated on $2^{2}$ wide portable track.

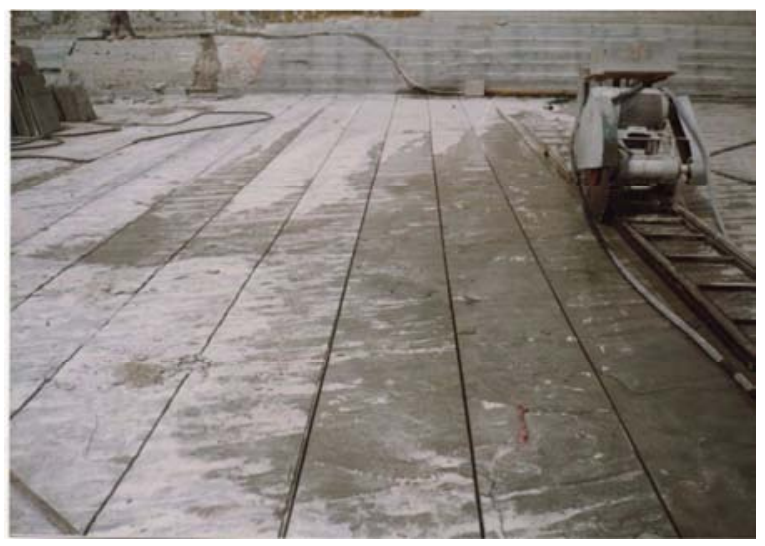

Figure 5. Jhiri Machine Cutting Kotah Stone Layers at 2 ft interval.

Water at pressure is forced into slit cool the cutting tool and also flush out the cutting slurry. The machine is operated at given peripheral speed of $33-36 \mathrm{~m} / \mathrm{sec}$ which cuts layers to a depth of $12 "$ at a linear speed of $30 " /$ mint.

In this system there is hardly any breakage except when there is a natural crack. Physical human efforts has substantially reduced leading to increase in productivity to 2.5 times. Density of employment reduced from 1 to 0.4 per square 100 sqft floor area providing more walking space. Earlier with manual mining layers only -3 " thick were mined and rest were thrown as waste. But with mechanised mining all solid layers irrespective of thickness are being mined successfully. This has improved mineral conservation appreciably.

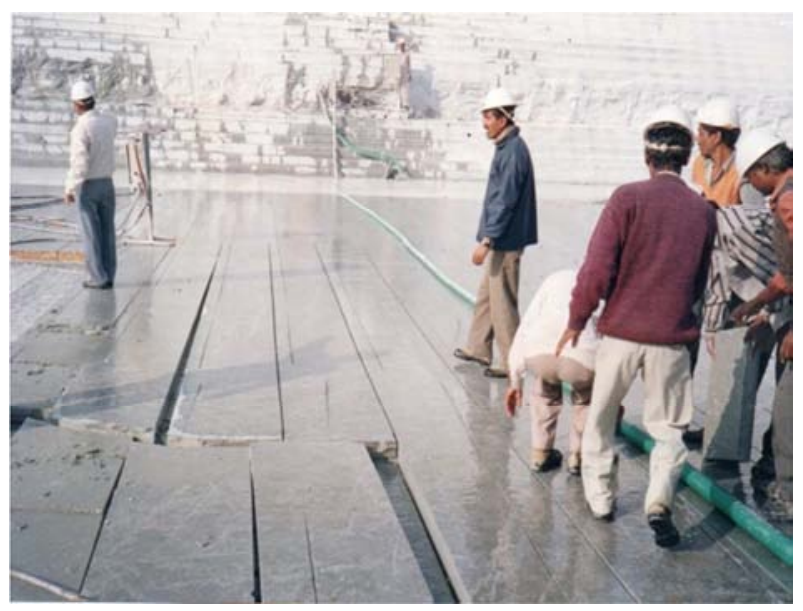

Figure 6. Working of Thickest Layer of Kotah Stone.

\section{Safety Standards with Innovative Mining Technology}

The innovated clean technology has eliminated quite a few manual process which were hazardous and main cause of personal injuries and ordeous. Its impact on personal safety of mine worker and injury rate are detailed below:

\subsection{Reduction in Accidents During Recess Cutting}

Manual recess cutting by chiesel and hammer has been totally eliminated and instead layers are cut mechanically. This has eliminated the injury to eyes and crush injury to thumb or fingers.

\subsection{Reduction in Accidents During Separating Layers}

No more big chunk of layer is separated now, lifted and turned upside down. Instead all sides cut smaller blocks are separated and lifted easily. This has reduced undue fatigue, accidental breakage, or injury due to slipping of crowbar or over stressing of spinal cord. Total human efforts are now utilised productively resulting in higher productivity with higher earning with reduced body fatigue.

\subsection{Reduction in Accidents Due to Clean Quarry Floor}

Due to in-situ cutting, production waste reduced substantially keeping quarry floor clean. This has reduced the risk and injury from knocking down or slipping. Many injuries of leg, foot and even fatal injuries have been eliminated. With clean floor it has been possible to deploy light tyre mounted loader/scrapper to sweep the floor and clean the waste, reducing manual engagement for the purpose.

\subsection{Reduction in Accidents by During Handling of Kotah Stone Slabs/Tiles}

Earlier entire production in form of slabs/tiles was carried out of quarry floor as head load for loading trucks for transportation to surface. Now trucks come directly on quarry floor close to stacks avoiding accidents during manual handling. 


\subsection{Reduction In Accidents Due To Improved Working Environment}

When at work human body produces a lot of waste energy which has to be dissipated in the surrounding to keep body temperature in limits. When the heat dissipating mechanism fails or retards the body temperature rises beyond $39^{\circ} \mathrm{C}$, may lead to heat stroke, heat exhaustion or mental fatigue. All these disorders lead to depression, rebellious attitude and carelessness. This became the potential cause of accident.

Such has been the working environment with manual mining of Kotah Stone. During summer time extending from April to June, ambient temperature rises as high as $47-49^{\circ} \mathrm{C}$. In the conventional manual mining with large workforce, there have been many cases of exhaustion due to heat and mental fatigue especially of female workers. At times this lead to fall from height which proved fatal.

With clean innovated technology water used at pressure for cooling cutting tool when ejects out the slit sprays all around creating cooling conditions.

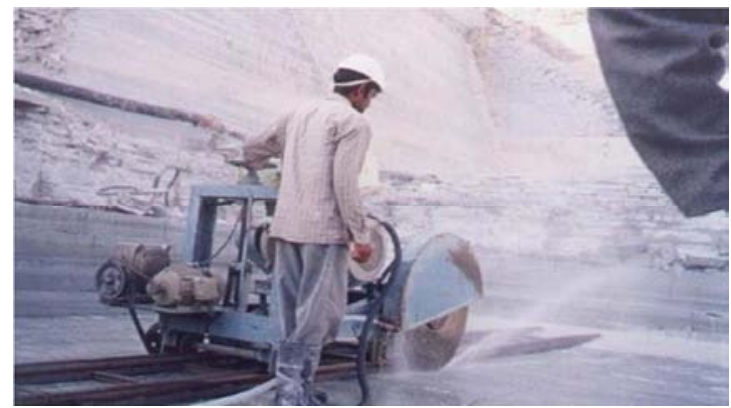

Figure 7. Cooling Water Ejecting out in form of Mist.

Hygrometer Survey was conducted by author about working comfort prevailing in the quarry both manually worked and worked with innovated technology during month of May, the peak summer month. The comparative results are tabulated below.

Table 1. Results of Hygrometer Survey.

\begin{tabular}{lllll}
\hline SI. No & Mode of Mining & Temp ${ }^{\circ} \mathbf{C}$ Dry Bulb & Temp Wet Bulb & Remarks \\
\hline 1 & At ground Level & 38 & 30.5 & \\
2 & Manual Mining & 35.5 & 31 & At quarry floor \\
3 & At 12m above the Working in Mechanised & 37.8 & 29.5 & $12 \mathrm{~m}$ above27m below GL 27th May the \\
quarry floor \&1.5m below GL \\
4 & Mechanised Quarry with one jhiri m/c at quarry floor & 37 & 28 & $22 \mathrm{~m}$ below GL on 27th May at 10.30AM \\
5 & Inside office cooled with desert cooler & 33 & 28 & On 27th may at 3 PM \\
\hline
\end{tabular}

From the survey studies it is revealed that the working comfort at the pits worked with innovated technology is far better than in manual mines. The working environment is surprisingly found to be as comfortable and cool as in the office room cooled with desert cooler.

All these changes in working environment has helped in maintaining mental order, tolerance and alertness of the workers against any danger or accident. The clean and cool environment has not only reduced accidents to $1 / 6$ th but also helped in improving the work efficiency by 3.5 times.

\section{Improved Welfare Conditions}

The innovated technology proved to be blessings for the mine worker to multiply their earning because of increased productivity. Prosperity keeps the worker and his family happy. A happy worker is a safe worker, undoubtedly.

Conventional manual mining has led to many Environmental problems which have direct impact on the people living around the mine area. Fast depletion and nonconservation of top precious soil has reduced agriculture proceed, grass grazing land for cattles and fast runoff of rain water. The availability of drinking water had been decreasing year after year. It had taken dimension day to day living difficult. Inspite of 33" average rain fall Govt laid pipeline at a cost of RS $15 \mathrm{cr}$ for providing drinking water from a dam located some $70 \mathrm{kms}$.

Innovated clean technology has brought some relief by deferring dewatering of rain water from quarries by spreading from 3 months to 6 months. Water is now available even in peak summer months for washing, bathing, cleaning and agriculture. Both. The innovated clean technology has definitely long term effect on workers' health. A healthy worker is safe worker less prone to accidents. This is concluded from the fact that absenteeism has reduced and workers are putting many more years of active and healthy life.

\section{Comparative Study of Safety Standards}

Comparative study of one largest mine revealed that:

With innovative mining technology the frequency of accidents and persons injured annually has reduced to less than $1 / 6$ th.

Number of persons injured annually in manual mining varied from 100 to as high as 286 but this has reduced as low as -46 with Innovative mining.

Mandays lost per Lac sqft of production reduced from 36.6 to as low as 13 only.

Mandays lost per Lac of mandays employed reduced from 1150 to 900 .

Mandays lost per accident has however increased from 15.8-20.5 to 27.3 - 35.5. It is because in Innovative Mining, though number of persons injured has reduced from 286 to 46 only but severity of injury was more for use of machines. This calls for improving skill of machines operators and general training. 


\section{Bench Slopes}

In an opencast mines stability of bench slope plays a crucial role in avoiding danger either from failures or any loose stone rolling down and hitting either man or machines. In manually worked mines bench height varied from $2 \mathrm{~m}$ to as high as $15 \mathrm{~m}$ sloping dangerously at $80-85 /$ from horizontal. Deposit being very comparative there has not been any incidence of slope failure but definitely it had exposed risk of stone rolling down at hitting the workers.

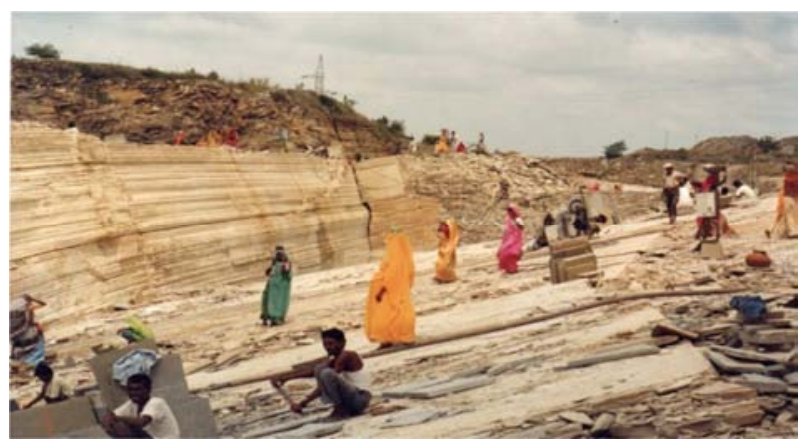

Figure 8. Manual Mining with High Bench Heights.

With innovative technology benches with nicely cut steps $6 "$ wide, 12" fall have been cut by machine sopping at safe angle of 55-60 degree from horizontal.

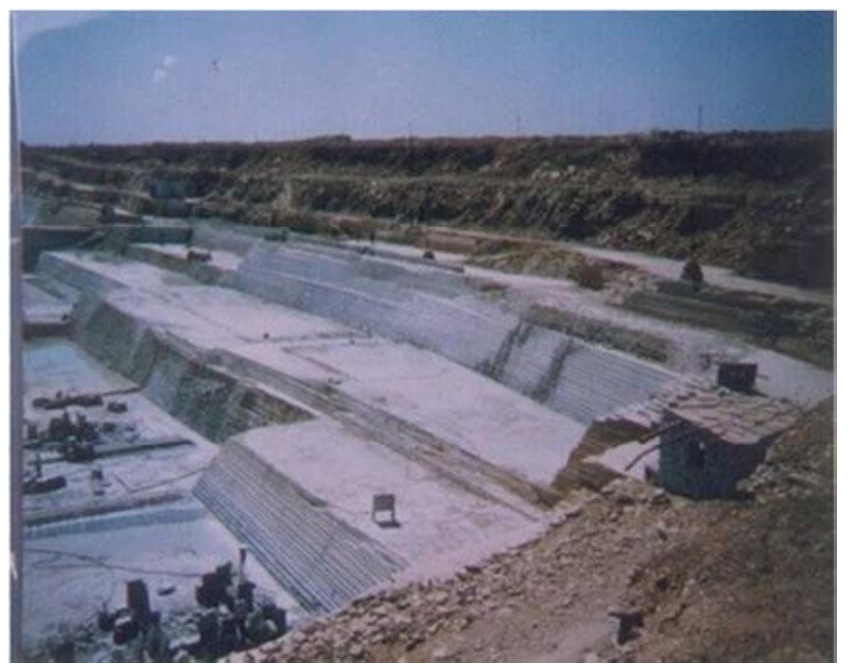

Figure 9. Long View of Query being worked with Innovative Technology.

\section{Haul Road Gradients}

In manually system the mine operators, except a organised group, had carried out mine operation in most hazardous way with benches not wide enough and un-safe gradient. This had forced vehicles to negotiate dangerously steep gradient. Such practice had been prime cause for many fatal accidents either by vehicle rolling down the steep gradient or turning side way and falling from height. Adding further to worse to it even the workers were permitted to either ride such vehicles or walk along roads.

All such unsafe layouts and practices have been totally eliminated in quarries worked with innovated technology. Regular benches both in $\mathrm{OB}$ and production zone are provided with adequate width and gently sloping. This has minimised haul road accidents to almost zero. The haul roads are construed tough enough to bear loads and maintained regularly to safe standards.

\section{General House Keeping}

General housekeeping and tidiness plays an important role in any industry including mining to improve work efficiency and avoid incidence leading to personal injury. The innovated technology provides a tidy and clean look of working floor which appeals everyone to stay on at workplace to work and work.

\section{Findings}

The innovative mining technique proved to be Responsible and Best Mining Practice. Responsible practice is defined as practices that are widely recognised by interested stakeholders as being the most effective way to achieve agreed goals, given the current state of knowledge. The Responsible innovated mining technology in Kotah Stone has proved to be blessing for mine workers and their family in multiplying their earnings because of increased productivity, improved working conditions and enhanced welfare, prosperity of workers and their families. Prosperity keeps the worker and his family happy. It has ensured high conservation of unique deposit of Kotah Stone widely known as best and most economical flooring stone.

\section{References}

[1] Agarwal, S. C., "Sustainable Rural Development through Responsible Mining of Natural resources of Kotah Stone in Rajasthan", 31st Indian Engineering Congress, IEI (India), 16.08.2016, Kolkata.

[2] Agarwal S. C., " Clean Technology is Safe Technology: A Success Story of Dimensional Limestone", 19 th World Mining Congress, New Delhi, 1-5 th November, 2003.

[3] Agarwal, S. C., " Practice, Procedure \& Draft Policy for Environmental Protection in Kotah Stone Mining", 19 th World Mining Congress, New Delhi, 1-5 th November 2003.

[4] Prasad S. N, Sethy B. K. \& others, "Natural Resources for Sustainable Development in Western India", ICAR, GOI.

[5] Agarwal S. C., " Trends in Technological Development in Kotah Stone Mining- A Critical Review of Resources Saving"; 16 th World mining Congress, Sofia Bulgaria, 11-16 th September, 1994.

[6] "Dimensional Stone Mining", Proceedings of Centennial Celebration Directorate General of Mine Safety, GOI, Dhanbad, 7-8 th January 2002. 
[7] Agarwal, S. C. "Economics of Solid Waste Management and Technology in Dimensional Limestone Mining: A Case Study" 11th International Conference on Solid Waste Technology and Management, Philadelphia, USA, 12-15 th November, 1995.

[8] Agarwal S. C. Innovating a Clean Technology for Mining Kotah Stone and Sharing Gains; First World Mining Environment Congress, New Delhi 11-14 th December, 1995.

[9] Agarwal, S. C., "Clean Technology is the Safe Technology: A Success Story of Dimensional Limestone Mining", Environmental Issues and Waste Management in Energy and Mineral Production,-SWEMP-98 Ankara, Turkey, 18-20 th May 1998.

[10] The Coal and Metalliferous Mines Regulations; Directorate General of Mine Safety, Ministry of Labour and Employment, Government of India, 2017 \& 2019.
[11] 'Safety and Environmental Standards", Innovative Responsible Mining Assurance (IRMA) Standards - 2016.

[12] Agarwal S. C., "Kotha Stone Quarry Waste; An Economical Source of Quick Lime in Lime Stabilisation of Soil in Rural Roads ", 16 th International Symposium on Environmental Issues and Waste Management in Energy and Mineral production, SWEMP 2016.

[13] Miner's Health and Safety Issues, Mining Review, Africa.

[14] Indian Standards IS $+18001-2007$ for Occupational Health and Safety Management System.

[15] GOI Survey Report on Occupational Health of Workers Employed in Stone Mines, Dec, 2015. 